\title{
A 55-year-old man with chest pain and a common but bewildering cause
}

\author{
Ting $\mathrm{Yi}^{1}$, Rui Guo ${ }^{2}$, Xiaogang $\mathrm{Li}^{3}$, Liping Peng ${ }^{3}$ \\ ${ }^{1}$ Department of Hematology, Changsha Central Hospital, University of South China, Changsha, China; ${ }^{2}$ Department of Radiology, the 3rd Xiangya \\ Hospital, Central South University, Changsha, China; ${ }^{3}$ Department of Cardiology, the 3rd Xiangya Hospital, Central South University, Changsha, \\ China
}

Correspondence to: Xiaogang Li, MD; Liping Peng, MD. Department of Cardiology, the 3rd Xiangya Hospital, Central South University, No. 138, Tongzipo Road, Yuelu District, Changsha, China. Email: 598590212@qq.com; plpzs1@126.com.

Submitted Sep 05, 2021. Accepted for publication Dec 07, 2021.

doi: 10.21037/qims-21-890

View this article at: https://dx.doi.org/10.21037/qims-21-890

\section{Case presentation}

All procedures performed in this study were in accordance with the ethical standards of the institutional and/or national research committee(s) and with the Helsinki Declaration (as revised in 2013). Written informed consent was obtained from the patient for publication of this case report and accompanying images. A copy of the written consent is available for review by the editorial office of this journal.

A 55-year-old man with a history of hypertension and cholecystitis was admitted to our ward with 3-year history of paroxysmal chest pain that had worsened in the past 1 day. His blood pressure (BP) was very well controlled on amlodipine. Electrocardiography performed in the emergency room indicated myocardial ischemia and a slightly increased troponin I level. Acute coronary syndrome (ACS) was initially suspected. However, coronary angiopraphy revealed a normal coronary artery except for the myocardial bridge of the left anterior descending artery, and abnormal vascular communication was noted between the coronary arteries and outside the heart. Coronary artery and lung computed tomography (CT) scanning revealed these communications, as well as pulmonary artery embolisms (PE) of the left and right pulmonary artery trunks. However, he was asymptomatic during normal activity when he was not experiencing chest pain during the previous 3 years, and no risk factors for PE were identified. Therefore, what was the main cause of his chronic chest pain and PE? He had no recent history of alcohol or drug used, although he had a 2 pack/day cigarette smoking and sedentary history.

\section{Physical examinations}

Upon admission to our ward, his vital signs were as follows: temperature, $36.5^{\circ} \mathrm{C}$; pulse $104 \mathrm{bpm}$; respiration $20 \mathrm{bpm}$; BP 115/75 mmHg; and oxygen saturation, 98\%. A general examination of the lungs, heart, and abdomen revealed no significant findings.

\section{Laboratory and radiography tests}

Routine blood, urine, stool, liver and renal function, coagulation function, and b-type natriuretic peptide level tests were normal. Myocardial enzymes were as follows: myoglobin, $91.8 \mathrm{ng} / \mathrm{mL}(\uparrow)$, lactate dehydrogenase $(\mathrm{LDH})$ $441 \mathrm{U} / \mathrm{L}(\uparrow)$, and creatine kinase $\mathrm{Mb}(\mathrm{CK}-\mathrm{Mb})$ was normal; troponin-I, $0.38 \mathrm{ng} / \mathrm{mL}$ (1st time) $\uparrow$ and $0.45 \mathrm{ng} / \mathrm{mL}$ $\left(2^{\text {nd }}\right.$ time $)(\uparrow)$; D-dimer 821.66 fibrinogen equivalent units (FEU)/mL (reference value: 0-500 FEU/mL). Blood gas analysis results were: normal. Plasma homocysteine was $27 \mu \mathrm{mol} / \mathrm{L}$ (reference value: $3-10 \mu \mathrm{mol} / \mathrm{L}$ ). Protein C level was: $53 \%(\downarrow)(82-112 \%)$, and anti-thrombin III $152 \%(\uparrow)$ (80-120\%).

Emergency room electrocardiography showed sinus tachycardia (103 bpm), normal axis, incomplete right bundle branch block, and ST-T depression of leads I, avL, and V5-6. (Figure 1, upper panel shows the emergency room 


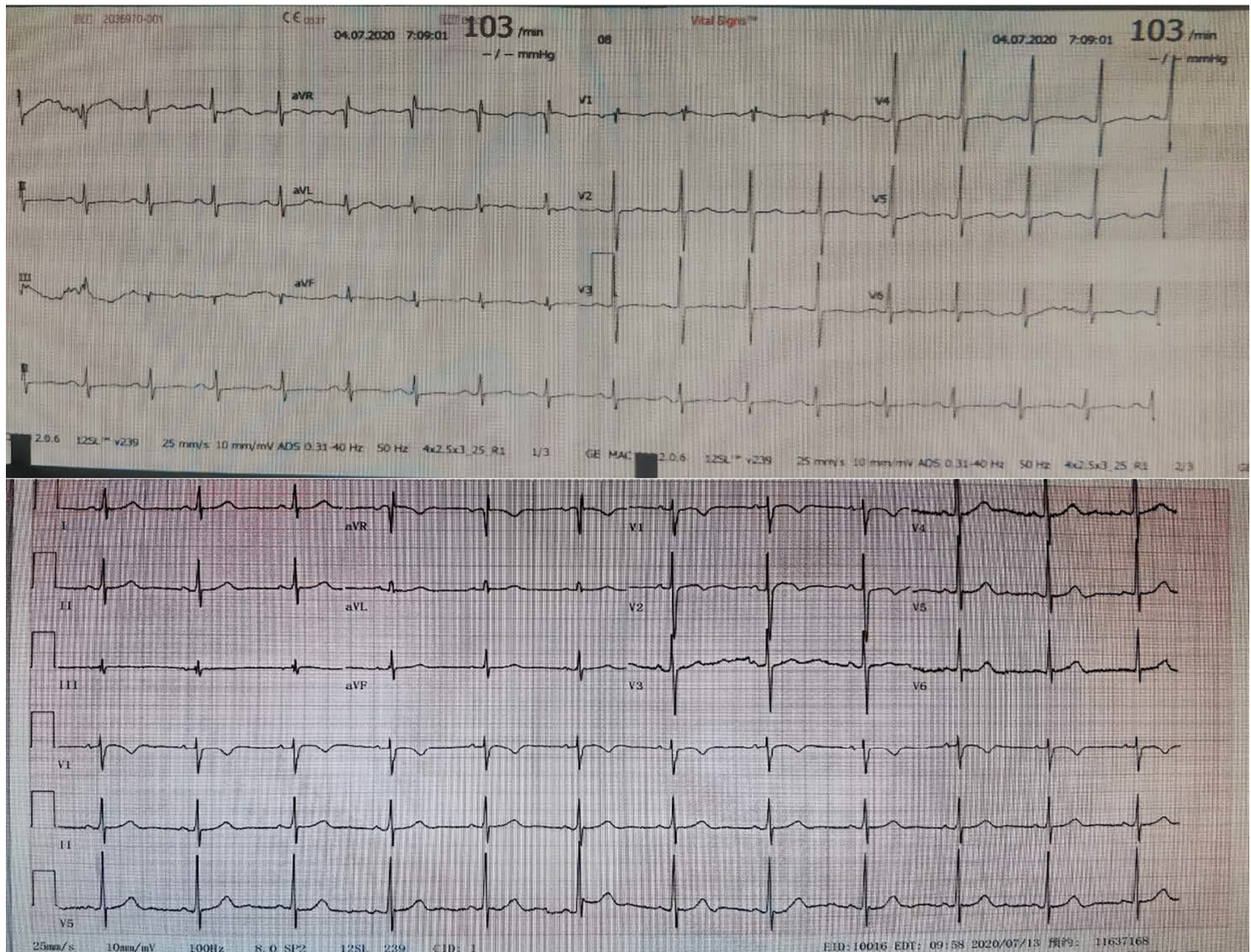

Figure 1 Electrocardiogram (ECG) from the in emergency room (upper) and the reexamination in our ward (lower).

test; lower panel shows the reexamination performed in our ward). Cardiac ultrasound showed no enlargement of the atria and ventricles and normal pressure of the pulmonary artery.

Chest radiography was notable for bronchitis. Coronary angiography revealed a normal: left main coronary artery, circumflex artery (LCX), and right coronary artery (RCA) were normal. The syntax score was 0 . However, it showed two abnormal arterial communications, one between the LCX and outside the heart, and the other between the RCA and outside the heart (Figure 2 coronary angiogram). Coronary artery and lung CT scans revealed extra-cardiac communications (Figure $2 \mathrm{CTA}$ ). Interesting, the left and right brunches of the pulmonary artery were almost completely blocked, and lung CT indicated a pulmonary artery embolism of the left and right brunch (Figure 3). CT, computed tomography; LCX, circumflex artery; RCA, right coronary artery.

\section{Discussion}

Chest pain is commonly encountered symptom, especially in the emergency room, that bewilders younger doctors who lack extensive clinical experience. In this case, a 55 -year-old man with chest pain underwent tests to evaluate the usual reasons for chest pain. However, we excluded the most common reasons, such as ACSs and aortic dissection, pulmonary artery embolism (PE), and thrombosis in the lower extremity veins. Although $\mathrm{PE}$ is not rare in the clinic, multiple thromboses can occur in the lower extremity veins, while meanwhile coronary-pulmonary artery fistulas are uncommon, and it is interesting to note that he did not have very serious dyspnea.

$\mathrm{PE}$ is a common emergent disease that manifests as dyspnea, chest pain, hemoptysis, or cardiac arrest (1). It must be distinguished from ACS or aortic dissection (2). However, this case involve no symptoms of $\mathrm{PE}$, no obvious 
CAG-A

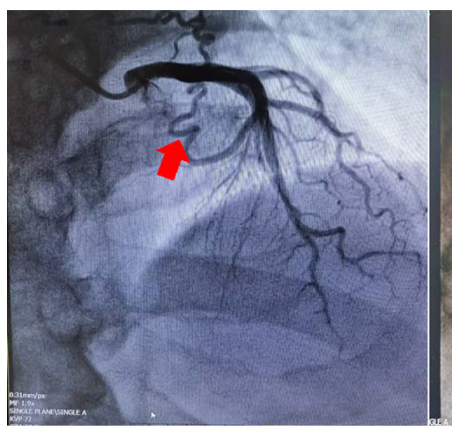

CAG-C

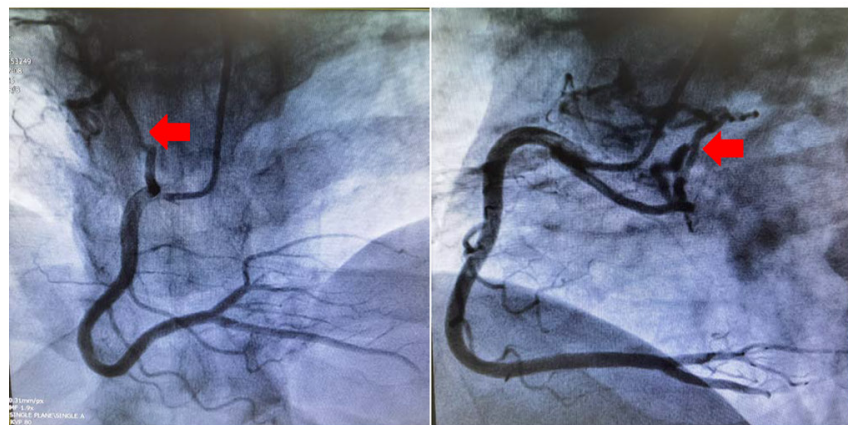

CAG-B

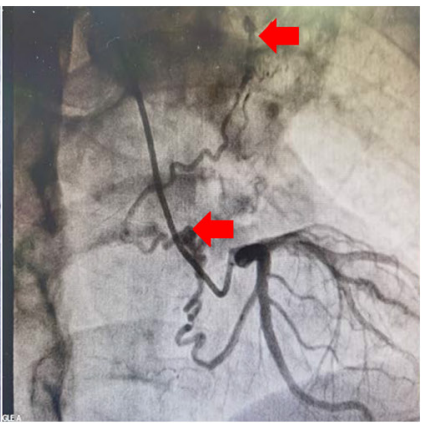

CAG-D
CTA-A

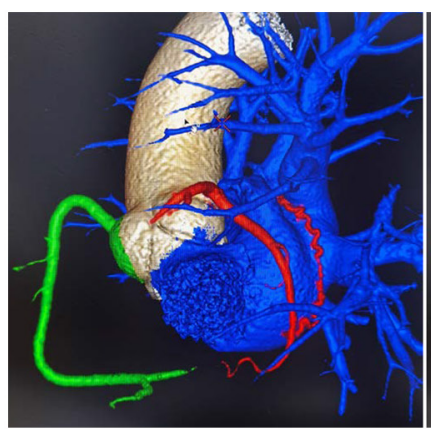

CTA-C
CTA-B

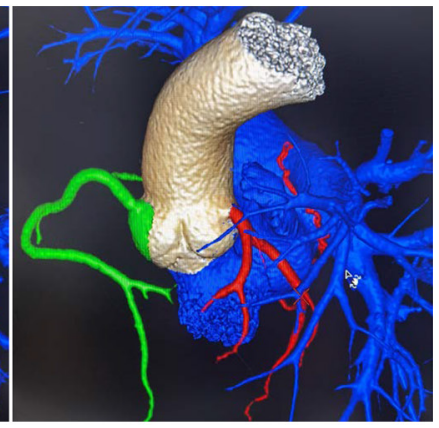

CTA-D

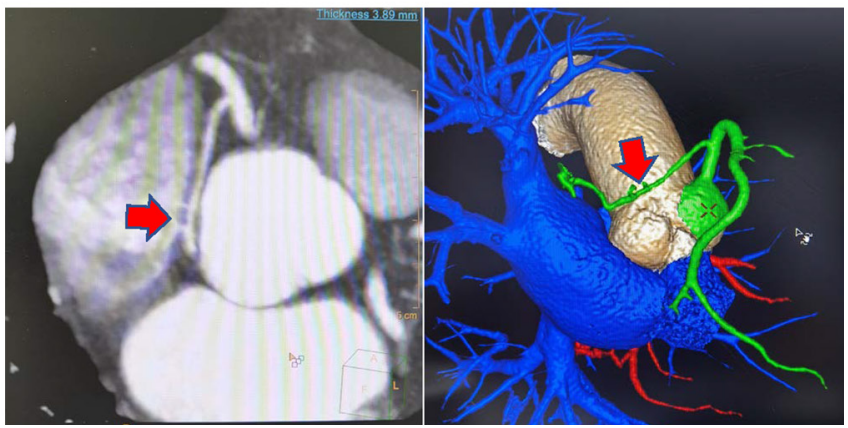

Figure 2 Coronary angiograph showing communication between the LCX and outside the heart and as well as between the RCA and outside the heart (the abnormal artery is pointed by red arrow, CAG-A,B,C,D). Coronary CT angiography shows detailed links of the coronary lateral branch, one arterial communication between the LCX and the left superior pulmonary vein (CTA-A,B) and the other among the RCA, right atrium (CTA-C) and left atrium (CTA-D). LCX, circumflex artery; RCA, right coronary artery; CTA, computed tomography angiography.

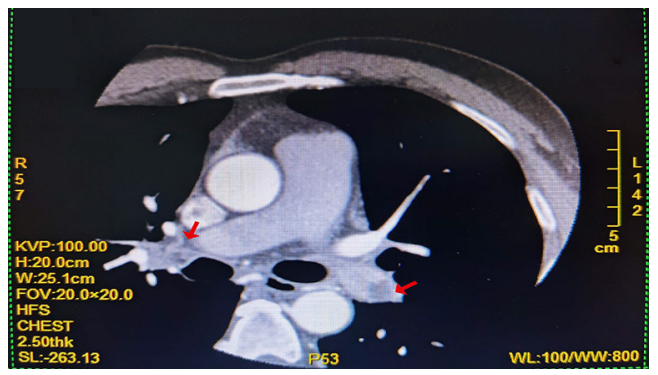

Figure 3 The filling defects in the left and right pulmonary arterial trunk (red arrow). Low-extremity vascular ultrasound showing multiple thromboses in the popliteal, iliac, and femoral veins.

dyspnea, and no hemoptysis. Dynamic changes were noted in plasma troponin I and ECG findings. CAG demonstrated no evidence of ACS, but abnormal arterial communications between the coronary and outside the heart were noted. These abnormal coronary arterial communications were considered coronary artery fistulas.
Extra-cardiac collaterals to the coronary arteries are not rare and have been reported in recent years; these extracardiac collaterals are collectively coronary artery fistulas (3). Coronary artery fistula is almost always accompanied by congenital cardiovascular abnormalities, such as patent ductus arteriosus, ventricular septal defect, pulmonary atresia, pulmonary artery hypertension, or coronary arterial aneurysm $(4,5)$. Such abnormal communications are illuminated CAG, CT angiography, or cardiac ultrasound (6-8). We encountered a rare case of bilateral coronarypulmonary vein fistulas associated with $\mathrm{PE}$ with two fistulous tracts arose from the left and right coronary arteries to the pulmonary veins and serious $\mathrm{PE}$.

We think better of this case, PE might be associated with bilateral extra-cardiac communications, which increase pulmonary arterial pressure and slow the blood flow speed with the pulmonary artery, resulting in PE (9). To further investigate the causes of $\mathrm{PE}$, multiple thromboses were found in the popliteal, iliac, and femoral veins by lower limb 
vascular ultrasound; and this is the most common cause of PE. The coagulation test results were normal for clotting disorders or thromboembolic disease, but protein $\mathrm{C}$ level was significantly increased. Many researchers have reported that high levels of plasma homocysteine inhibit protein $\mathrm{C}$ activity and affect the coagulation system, leading to PE (10). This patient had a high level of homocysteine, which might have placed him at high risk of venous thrombosis. Meanwhile, hematologic experts believe that thrombophilia should be considered in this case because of his clinical manifestations and high protein $\mathrm{C}$ level. The cause of the $\mathrm{PE}$ and vein thrombosis was considered thrombophilia. In addition, homocysteine is a vital and dependent risk factor for PE. We used folic acid tablets to reduce his plasma homocysteine level to decrease his risk of re-thrombosis. Meanwhile, rivaroxaban was used for anticoagulation (11); fortunately, he had no venous thrombosis 1 month later. We continue to follow-up with him. We also suggested blocking the fistulas with coronary artery coils (12), but the patient refused. Therefore, the final diagnosis was: (I) thrombophilia, low extremity venous thrombosis and pulmonary artery embolism; and (II) coronary artery fistula.

\section{Conclusions}

Although our patient had chest pain, an increased troponin I level, and abnormal ECG findings, we need to consider $\mathrm{PE}$ in the differential diagnosis. In this case, multiple communications among the LCX, RCA, right atrium, and pulmonary vein might have been associated with $\mathrm{PE}$. According to the protein $\mathrm{C}$ activity test, we considered thrombophilia the main cause of the multiple thromboses in the lower extremity and pulmonary artery, for which hyperhomocysteinemia required treatment with folic acid at an early stage.

\section{Acknowledgments}

Funding: The work was supported by the National Natural Science Foundation of China (NSFC) Projects (No. 81800271 ) and the Natural Science Foundation of Hunan Province (Nos. 2019JJ50920 and 2021JJ40625).

\section{Footnote}

Conflicts of Interest: All authors have completed the ICMJE uniform disclosure form (available at https://qims. amegroups.com/article/view/10.21037/qims-21-890/coif).
The authors have no conflicts of interest to declare.

Ethical Statement: The authors are accountable for all aspects of the work in ensuring that questions related to the accuracy or integrity of any part of the work are appropriately investigated and resolved. All procedures performed in this study were in accordance with the ethical standards of the institutional and/or national research committee(s) and with the Helsinki Declaration (as revised in 2013). Written informed consent was obtained from the patient for publication of this case report and accompanying images. A copy of the written consent is available for review by the editorial office of this journal.

Open Access Statement: This is an Open Access article distributed in accordance with the Creative Commons Attribution-NonCommercial-NoDerivs 4.0 International License (CC BY-NC-ND 4.0), which permits the noncommercial replication and distribution of the article with the strict proviso that no changes or edits are made and the original work is properly cited (including links to both the formal publication through the relevant DOI and the license). See: https://creativecommons.org/licenses/by-nc-nd/4.0/.

\section{References}

1. Böttiger BW, Wetsch WA. Pulmonary Embolism Cardiac Arrest: Thrombolysis During Cardiopulmonary Resuscitation and Improved Survival. Chest 2019;156:1035-6.

2. Pulmonary embolism. Nat Rev Dis Primers 2018;4:18031.

3. Mangukia CV. Coronary artery fistula. Ann Thorac Surg 2012;93:2084-92.

4. Yang S, Liang M, Chen G, Yang M, Wu ZK. Giant Coronary Artery Aneurysm Combined Coronary Right Ventricle Fistula. Circ Cardiovasc Imaging 2020;13:e010166.

5. Merchant Z, Alfirevic A. Holodiastolic Flow Reversal in Descending Aorta with Right Coronary Artery to Coronary Sinus Fistula. Anesthesiology 2019;131:1340-1.

6. Shi K, Gao HL, Yang ZG, Zhang Q, Liu X, Guo YK. Preoperative evaluation of coronary artery fistula using dual-source computed tomography. Int J Cardiol 2017;228:80-5.

7. Kim H, Beck KS, Choe YH, Jung JI. Coronary-toPulmonary Artery Fistula in Adults: Natural History and Management Strategies. Korean J Radiol 2019;20:1491-7. 8. Yun G, Nam TH, Chun EJ. Coronary Artery Fistulas: 
Pathophysiology, Imaging Findings, and Management. Radiographics 2018;38:688-703.

9. Miura S, Naya M, Manabe O, Ando A, Usami A, Miyazaki C, Yamashita T, Ohkawa Y. Effects of ligation of a coronary artery fistula on coronary blood flow. J Nucl Cardiol 2019.

10. Di Nisio M, van Es N, Büller HR. Deep vein thrombosis and pulmonary embolism. Lancet 2016;388:3060-73.

11. Kearon C, Akl EA, Ornelas J, Blaivas A, Jimenez D,

Cite this article as: Yi T, Guo R, Li X, Peng L. A 55-yearold man with chest pain and a common but bewildering cause. Quant Imaging Med Surg 2022;12(4):2586-2590. doi: 10.21037/ qims-21-890
Bounameaux H, Huisman M, King CS, Morris TA, Sood N, Stevens SM, Vintch JRE, Wells P, Woller SC, Moores L. Antithrombotic Therapy for VTE Disease: CHEST Guideline and Expert Panel Report. Chest 2016;149:315-52.

12. Bagul PK, Phadke MS, Kerkar PG. Percutaneous Closure of Left Main Coronary Artery Fistula Using AMPLATZER Vascular Plug II and AMPLATZER Duct Occluder I. JACC Cardiovasc Interv 2016;9:e67-70. 